\section{VBR 22}

CALCITONIN BINDING SITES AND CAICITONIN-RESPONSTVE ADENYLATE CYCLASE ACTIVITY IN SMALL CELL LUNNG CAREINOMA CELL LINES

M. Rotsch, G. Bepler, M. Häder and G. Jaques

The incidence of paraneoplastic syndromes in lung cancer, however, is only $3 \%$ although elevated peptide hormone levels in sera are found in up to $80 \%$ of all patients (Gropp et al., Verh. Dtsch. Krebsges. 4, 775, 1983). Small cell lung cancer shares a variety of neuroendocrine properties with these described normal cells (Carney et al., Cancer Res. $45,2913,1985)$. This endocrine differentiation can also be demonstrated by the production of various peptides, neuron-specific enolase, L-dopa decarboxylase, and the BB-isoenzyme of creatine kinase. The role of these peptides as tumor growth factor is currently under intensive investigation. First results have been obtained for bombesin and physalamin (Cuttitta et al., Nature 316, 823, 1985; Bepler et al., J. Cancer Res. Clin. Oncol. 109, A 21, 1985). The hypothesis proposes that carcinoma cells produce and secrete their own proliferation factors which interact with specific membrane receptors on their surface. We and others have established a large number of continuously growing cell lines derived from small cell lung carcinoma. These cell lines were cultivated from biopsy material of patients with histologically proven small cell lung carcinom. The study we present here is restricted to calcitonin, a peptide hormone that is frequentiy elevated $(60 \%)$ in the sera of small cell lung carcinoma patients. Several of our cell lines produce calcitonin. We have examined whether they have specific calcitonin binding sites and have tried to obtain data concerning the second messenger. Our resuits indicate that small celi lung carcinoma cell lines which produce calcitonin have a high affinity binding site for calcitonin but a low number of binding sites. We also found an increase of cyclic AMP concentrations in cell preparations following incubation with increasing amounts of calcitonin. These results are strong evidence for the presence of a receptor which uses the adenylate cyclase system as second messenger. Preliminary results indicate that calcitonin does not effect the cell growth directly. Whether this hormone effects the proliferation indirectly, i.e. through interaction with other growth factors, remains to be determinea.

Zentrum für Innere Mediz in der Philipps-Iniversität, Abt. Hämatologie/ Onkologie, Baldingerstrasse, D-3550 Marburg

\section{VBR 23}

HOMOGENEOUS GROWTH OF TUMOR CELI COLONIES IN AGAR CONTAINING GLAS CAPILLARIES B.Lathan. K. Kerkhoff, W. Scheithauer, V. DiehI The human tumor cloning system by Hamburger and Salmon has shown its potential as a method for prediction of response of an individual patients tumor to an antitumor agent. Maurer (Naturwiss. $67: 381-382, \quad 1981$ ) and Von Hof f (Proc.AACr $24: 310,1983$ ) have proposed the utilisation of agar containing glas capillaries instead of petri dishes to utilize less tumor cells and to increase the cloning efficiency ( $C E$, no.of colonies formed no.of cells plated). Since the optimal conditions for colony growth in capillaries have not been established yet, the study presented here was initiated. The study focused on 5 human tumor cell lines to provide reproducable conditions. The volume of the agar/cell suspension filled into each capillary tube had a major impact on the CE. Sufficient colony growth was achieved at both ends of the eapillaries, but due to poor growth in the middle of the tubes the CE was low when the tubes were completly filled. In contrast, homogeneous growth was achieved utilizing low filling volumes (i.e. $30 \%$ ) with subsequent increase in the CE. The size of tumor colonies was similarely influenced. The CE was higher in small tubes (i.e. 0.9 and $1.2 \mathrm{~mm}$ i.d.) compared to large tubes (i.e. 1.4 to $1.9 \mathrm{~mm}$ i.d.). Highest $\mathrm{CE}$ with homogeneous growth was achieved when capillary tubes of 1.2 $\mathrm{mm}$ i.d. filled with $30 \mu \mathrm{l}$ were utilized. Sealing both ends of the capiliary tubes did not influence the CE, provided that 10 mM HEPES buffer was used. These findings are of interest for future work with the capillary cloning system, since homogeneous growth is essential for in vitro drug sensitivity testing.

I. Medizinische Klinik der Universität Köln, Joseph-Stelzmann-Str. 9, D-5000 Köln 41
VBR 24

COLONY INHIBITION OF HUMAN TUMOR XENOGRAFTS IN VITRO BY FACTOR AF2

G.H. Leder, H.H. Fiebig, K.H. Widmer, H. Arnold

Liver and spleen extract from lamb mainly consisting of polypeptides (Factor AF2, Fa. biosyn, Ludwigsburg) showed tumor response in some patients with malignant disease as single agent or together with chemotherapy (Röhrer, personal communication). At present the mechanism of the possible efficacy of AF2 is quite obscure. Besides a stimulation of the immune system a direct cytotoxic effect can be presumed. As demonstrated in the table a modified Hamburger a Salmon assay revealed some dose responding effects of AF2. For the determination of the relevant dose in-vitro the most sensitive tumors are being studied in-vivo in nude mice.

Effects of Factor AF2 in the colony assay

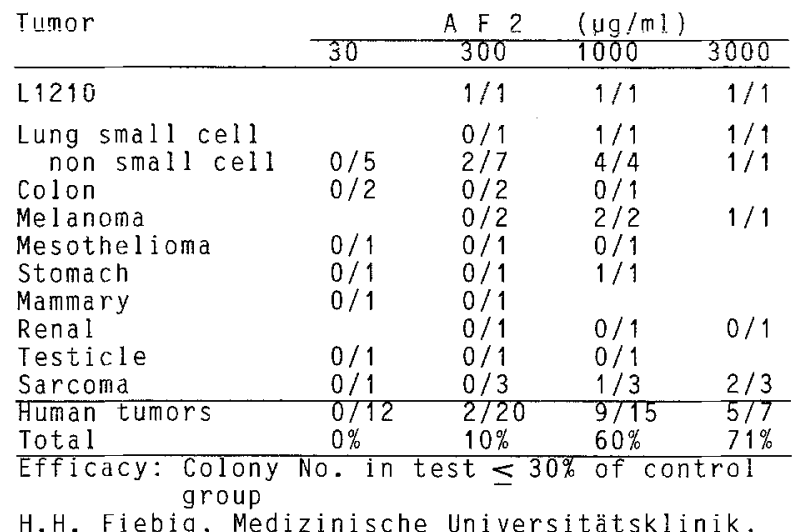
Hugstetter Str. 55, D-7800 Freiburg i.Br.

\section{VBR 25}

MECHANISM OF TPA-REIEASE FROM TUMOR CEIJS AND THE SIGNIFICANCE FOR MEASUREMENT OF TPA-PLASMA VALUES P. Oehr, M. Krämer, B. Schult, G. Kamp and H. -J. Biersack In order to understand the release of TPA from tissue we studied tissue cultures, solid tumors in animals and human tumors and performed TPA-determinations in each group. We observed a sequential release of TPA from synchronized HeLa cells immediately after cell division and elevated TPA-levels in supernatants of non-synchronized HeLa cells after cell death caused by irradiation. Similar results were found in animal experiments and studies with patients. Nude rats with rapidly growing tumors with a size $>0,4 \mathrm{~g}$ showed an increase of TPA-levels in plasma. Irradiation of these tumors resulted in a short increase of TPA-values within the first two days. Later, the TPAlevels decreased or returned to normal. Similar results were found in studies of patients.

In contrast to tissue cultures where small numbers of cells can be associated with high plasma TPA-concentrations within a short time, a greater amount of solid tumor tissue is necessary to induce elevated TPA in plasma of tumor-bearing animals and patients. In contrary to TPA from the closed tissue culture system in which the half life of TPA might be mainly influenced by proteolytic enzymes, plasma TPA in the animal system is cleared from peripheral blood by liver metabolism. Elevated levels of TPA will only be present in plasma when the release rate of TPA from the tumor tissue to the blood is higher than the clearance rate from the blood. Our results include the fact that elevated TPA-values can appear in animals with tumors $<0,4 \mathrm{~g}$ after irradiation. An increase in TPA-levels in this case is a result of cell death and not of tumor proliferation. In patients this might indicate that the effectiveness of treatment should also be monitored in those individuals which do not exhibit elevated plasma values but have TPA-positive tumors.

Institut für klin. und exp. Nuklearmedizin der Universität Bonn, Sigmund-Freud-Straße 25, D-5300 Bonn 1 